\title{
Schistosoma Hematobium-Related Bladder Verrucous Carcinoma
}

National Cancer Institute

\section{Source}

National Cancer Institute. Schistosoma Hematobium-Related Bladder Verrucous

Carcinoma. NCI Thesaurus. Code C39833.

A verrucous squamous cell carcinoma of the bladder that is caused by Schistosoma hematobium. 